\title{
USING OF VERSINE AND SAGITTA CALCULATIONS FOR LOG SAWING OPTIMIZATION, PART 1: CIRCULAR CROSS-SECTION
}

\author{
Hizir Volkan Gorgun ${ }^{1}$ \\ https://orcid.org/0000-0002-2537-2105
}

\begin{abstract}
Log sawing can be defined as a problem with obtaining squares from a cylindrical shaped raw material, log. There are traditional sawing methods such as live, cant, quarter, etc. for sawmills. However, they cant generally obtain maximum yield due to log and lumber variables for each log. Therefore, many mathematical approaches and computer programs were improved for log sawing. In this study, suitability of two geometrical calculations, versine and sagitta, were tried for log sawing process. Logs were assumed having cylindrical shape and circular cross section. The estimation accuracy of calculations was tested for live and can't sawing methods with in a drawing software. The results showed that one of versine equations works almost as well as the real dimensions. It is suggested that the equation can be used inside of algorithms for log sawing optimization. However, the real log defects such as taper, irregular cross-section, curvature, etc. should be considered for more realistic yield and accuracy.
\end{abstract}

Keywords: Log sawing, lumber optimization, sagitta, yield, versine.

\section{INTRODUCTION}

Log sawing can be defined as a problem with obtaining squares from a cylindrical shaped raw material. The calculation error causes worse sawing yield and economic losses for sawmills. Therefore, many approaches were tried for log sawing optimization; BOF (Best Opening Face), dynamic and heuristic programming, machine vision algorithms, AUTOSAW, GSS-A, GRASP A, KORKUT, TOPSAW computer programs, etc., (Hallock and Lewis 1971, Hallock et al. 1979, Faaland and Briggs 1984, Lewis 1985, Occeña and Tanchoco 1988, Todoroki 1990, Chang and Guddanti 1995, Occeña and Schmoldt 1995, Korkut 2004, Zheng et al. 2007, Bhandarkar et al. 2008, Lin and Wang 2012). In this paper, calculations of two geometrical approach (versine and sagitta) were tried for using in log sawing optimization. The suggested approaches, which were described in detail at below, tried to find accurately the relationship between slab thickness and width with using the trigonometric relations in unit circle. If a slab width could be estimated, first sawn board for live sawing or cant height for cant sawing can be calculated. In the literature theories suggested different approaches.

The Best Opening Face (BOF) (Lewis 1985) approach assumed logs as a truncated cone (three-dimensional) and consider fence setting in the calculations according to taper and different headrig systems. Due to fence considering saw kerf width with slab thickness, the calculations getting different and more complex. A two-dimensional geometric theory approach (Zheng et al. 2007) targets centered cant sawing solutions for both circular and elliptical shaped logs. The point of origin the approach was obtaining maximum cant cross-section area according to an elementary geometry principle. The principle indicates that a square has the greatest area of any quadrilateral inscribed within a circle. After obtaining ideal cant dimensions, the approach calculates ripping lumber in cant and sawing side boards from inside of the slabs. Many other solutions were not published due to being part of a commercial software (OpTimber 2020, Romware 2020, Saatech 2020, Tek1 Studio 2020). 
The "versine" or "versed sine" calculation is one of the trigonometric relations for some edges in unit circle (Figure 1). The versine of an angle is 1 minus its cosine. The term versine is also sometimes used to describe deviations from straightness in an arbitrary planar curve, of which the above circle is a special case. There are several related functions, most notably the coversine and haversine. Given a chord between two points in a curve, the perpendicular distance (versine) from the chord to the curve (usually at the chord midpoint) is called a "versine measurement" or "chord-method". This usage is especially common in rail transport, where it describes measurements of the straightness of the rail tracks (Boardman 1930, Nair 1972, Chiou and Yen 2019) and it is generally the basis of the Hallade method (Iwnicki 2006) for rail surveying (Inman 1835).

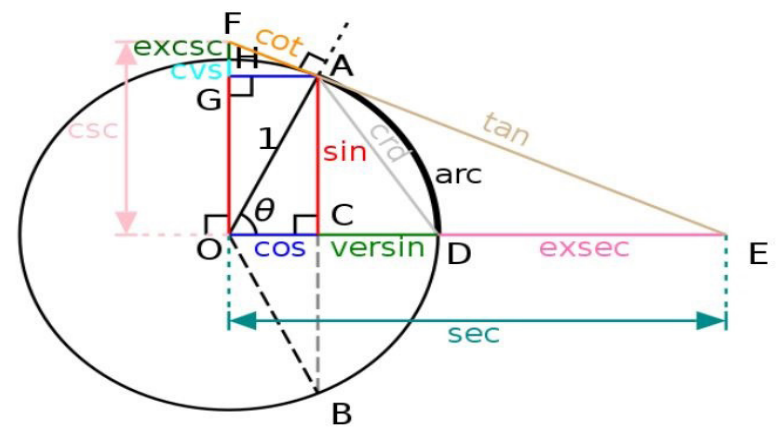

Figure 1: The trigonometric relations in a unit circle centered at $\mathrm{O}$ (Haslett 1859).

As seen in Figure 1, the edge of $|\mathrm{DO}|$ and edge of $|\mathrm{AO}|$ was radius. However, there are $(\theta)$ angle between them. In this case, edge of $|\mathrm{AC}|$ was $\sin (\theta)$ and edge of $|\mathrm{CO}|$ was $\cos (\theta)$. As a result, the edge of $|\mathrm{CD}|($ versine) can be calculated with these equations (Equation 1, Equation 2):

$$
\begin{aligned}
& |\mathrm{CD}|=|\mathrm{OD}|-|\mathrm{OC}| \\
& \text { Versine }=\text { Radius }-\operatorname{Cos}(\theta)
\end{aligned}
$$

In Figure 1, the edge of $|\mathrm{AB}|$ can be (which is two edges of $|\mathrm{AC}|$ for unit circle) assumed as slab width (sw), while the edge of $|\mathrm{CD}|$ (versine) slab thickness. If one of them was unknown, it could be found with versine calculations.

Similar approach can be seen for describing the surfaces of lenses and mirrors in optics with sagitta term. The sagitta (Latin arrow) can sometimes be substituted for versine (van Brummelen 2013). In the late $11^{\text {th }}$ century A.D., a solution (arc-sagitta method) for circular arc length in terms of chord length and the sagitta (middle ordinate) was presented by mathematician Shen Kua in his "Meng Chi Pi Than" book (Holzman 1958). The Sagitta of a circular arc is the distance from the center of the arc to the center of its base (Needham 1959, Woodward 1978, Martín et al. 2016).

However, most of equations for versine and sagitta have approximately equal symbol $(\approx)$, in other words they give approximate results. The log sawing is a practical operation and it needs certain results. Aim of this study to find an equation with giving certain results to use in log sawing optimization calculations. 


\section{MATERIAL AND METHODS}

\section{Equations}

There are some approaches for estimation the versine size according to versine calculation (chord method) and Sagitta method. (Equation 3, Equation 4, Equation 5, Equation 6, Equation 7, Equation 8).

$$
\begin{aligned}
& s t=\mathrm{r}-\sqrt{r^{2}-\frac{s w^{2}}{4}} \\
& s t \approx \frac{(s w / 2)^{2}}{2 r} \\
& s t \approx \frac{(s w / 2)^{2}}{2000 r} \\
& s t \approx \frac{s w^{2}}{8 r} \\
& s t \approx \sqrt{(|A D|-s w) r} \\
& s t \approx \frac{|A D|^{3 / 2}(s w / 2)^{1 / 2}}{8 r}
\end{aligned}
$$

Where; slab width (sw, mm), slab thickness (st, $\mathrm{mm}$ ), radius (r, $\mathrm{mm}$ ). In literature, there are more formula as seen in Equation 7 and Equation 8. However, they uses edge of $|\mathrm{AD}|$ (chord, crd in Figure 1) in calculations. The calculations were not used, because equations were becoming more than an unknown.

Additionally, the equations were only used for estimation the sizes of one-slab on live sawing. In addition to this, the equations could be used for the sizes of other slabs for cant sawing (Figure 2).

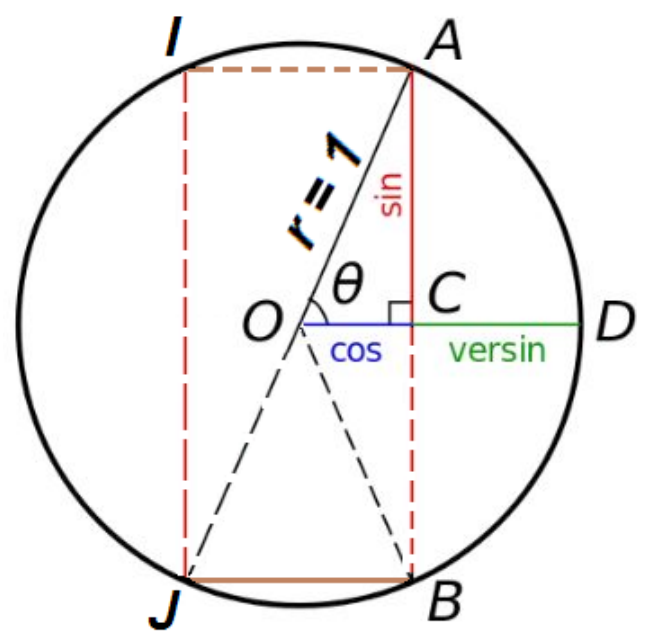

Figure 2: Other edges on unit circle for cant sawing. 
In Figure 2, the edge of $|A J|$ was diameter and edge of $|A B|$ was two edges of $|A C|(\sin \theta)$. When the $\mathrm{B}$ and $\mathrm{J}$ points were connected, JAB right triangle occurred. Thus, edge of $|\mathrm{BJ}|$ could calculated with using edge of $|\mathrm{AJ}|$, edge of $|\mathrm{AB}|$ according to Pythagorean relation (Equation 9, Equation 10, Equation 11).

$$
\begin{aligned}
& |\mathrm{AJ}|^{2}=|\mathrm{AB}|^{2}+|\mathrm{BJ}|^{2} \\
& |\mathrm{BJ}|^{2}=|\mathrm{AJ}|^{2}-|\mathrm{AB}|^{2} \\
& |\mathrm{BJ}|=\sqrt{|\mathrm{AJ}|^{2}-|\mathrm{AB}|^{2}}
\end{aligned}
$$

According to Figure 2, rectangle of AIJB could be assumed that it was a cant of a log. Edge of $|\mathrm{AB}|$ was cant height, edge of $|\mathrm{BJ}|$ was cant width. Then thickness of the slab from outside of the edge of $|\mathrm{BJ}|$ could be calculated with using the most accurate versine calculation.

\section{Test method and evaluation}

The accuracy of the calculations was tested in AutoCAD (2013) drawing software. A radius edge was drawn on horizontal axis. The radius edge was divided to the 10 parts with $10 \mathrm{~mm}$ intervals. Perpendicular edges until the circle were drawn from the interval points. Length of the perpendicular edge was considered as slab width (sw, mm). The distance between interval points and nearest circle point was considered as slab thickness (st, mm). Although the slab thicknesses were manually added, the slab widths were obtained from the software. All tests were performed on two circles with $30 \mathrm{~cm}$ and $40 \mathrm{~cm}$ diameter (Figure 3).

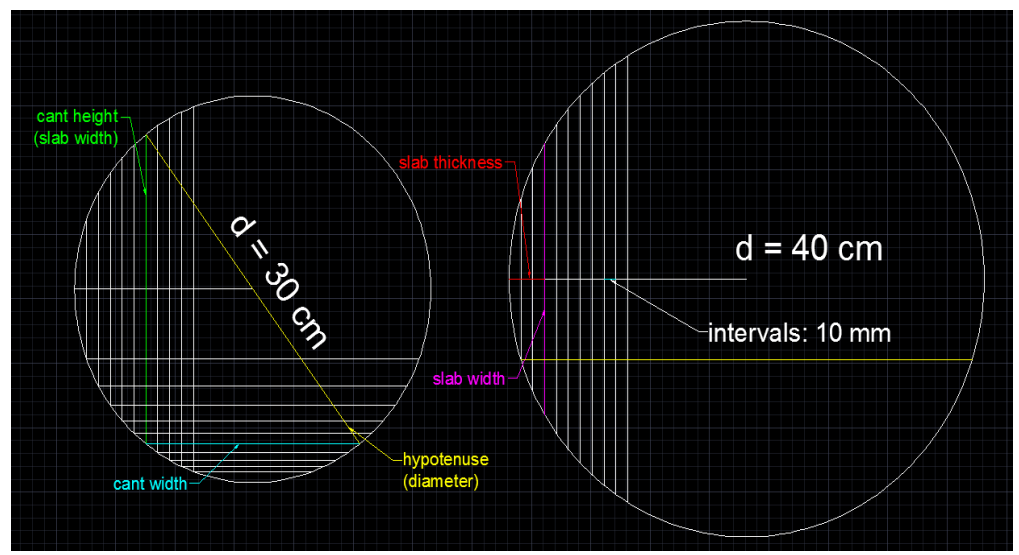

Figure 3: Drawings in AutoCAD (d: diameter).

The edges for live sawing were shown on $40 \mathrm{~cm}$ diameter circle, while the edges for cant sawing on $30 \mathrm{~cm}$ diameter circle in Figure 3. Cant width (cw) were estimated with using diameter and cant height (ct) according to Pythagorean relation. They were compared with drawn edges in AutoCAD.

The estimated slab widths, thicknesses and cant widths from versine and Pythagorean equations were compared statistically with drawing software results. The tested equations was for estimating board sizes before sawing. No or little differences were referred as accuracy test.

\section{RESULTS AND DISCUSSION}

\section{Live sawing}

The estimated values from the equations and distances from the software were compared and shown in Table 1 and Figure 4. 
Table 1: Accuracies of the equations for live sawing.

\begin{tabular}{|c|c|c|c|c|c|c|c|c|c|c|c|}
\hline \multicolumn{6}{|c|}{ Diameter: $300 \mathrm{~mm}$} & \multicolumn{6}{|c|}{ Diameter: $400 \mathrm{~mm}$} \\
\hline \multicolumn{2}{|c|}{$\begin{array}{l}\text { Software } \\
\text { Distance }\end{array}$} & \multirow{2}{*}{$\begin{array}{c}\text { Equation } 3 \\
\text { st }\end{array}$} & \multirow{2}{*}{$\begin{array}{c}\text { Equation } 4 \\
\text { st }\end{array}$} & \multirow{2}{*}{$\begin{array}{c}\text { Equation } 5 \\
\text { st }\end{array}$} & \multirow{2}{*}{$\begin{array}{c}\text { Equation } 6 \\
\text { st }\end{array}$} & \multicolumn{2}{|c|}{$\begin{array}{l}\text { Software } \\
\text { Distance }\end{array}$} & \multirow{2}{*}{\begin{tabular}{|c|} 
Equation 3 \\
st
\end{tabular}} & \multirow{2}{*}{$\begin{array}{c}\text { Equation } 4 \\
\text { st }\end{array}$} & \multirow{2}{*}{$\begin{array}{c}\text { Equation } 5 \\
\text { st }\end{array}$} & \multirow{2}{*}{$\begin{array}{c}\text { Equation } 6 \\
\text { st }\end{array}$} \\
\hline st & sw & & & & & st & sw & & & & \\
\hline 10 & 107,7 & 10,00 & 4,83 & 0,00 & 4,83 & 10 & 124,9 & 10,00 & 6,50 & 0,00 & 4,88 \\
\hline 20 & 149,7 & 20,01 & 9,34 & 0,01 & 9,34 & 20 & 174,4 & 20,01 & 12,67 & 0,01 & 9,50 \\
\hline 30 & 180,0 & 30,00 & 13,50 & 0,01 & 13,50 & 30 & 210,7 & 30,00 & 18,50 & 0,01 & 13,87 \\
\hline 40 & 204,0 & 40,02 & 17,34 & 0,02 & 17,34 & 40 & 240,0 & 40,00 & 24,00 & 0,02 & 18,00 \\
\hline 50 & 223,6 & 50,00 & 20,83 & 0,02 & 20,83 & 50 & 264,6 & 50,01 & 29,17 & 0,02 & 21,88 \\
\hline 60 & 240,0 & 60,00 & 24,00 & 0,02 & 24,00 & 60 & 285,7 & 60,02 & 34,01 & 0,03 & 25,51 \\
\hline 70 & 253,8 & 70,02 & 26,84 & 0,03 & 26,84 & 70 & 304,0 & 70,02 & 38,51 & 0,03 & 28,88 \\
\hline 80 & 265,3 & 79,97 & 29,33 & 0,03 & 29,33 & 80 & 320,0 & 80,00 & 42,67 & 0,03 & 32,00 \\
\hline 90 & 275,0 & 90,05 & 31,51 & 0,03 & 31,51 & 90 & 334,1 & 90,03 & 46,51 & 0,03 & 34,88 \\
\hline 100 & 282,8 & 99,94 & 33,32 & 0,03 & 33,32 & 100 & 346,4 & 99,99 & 50,00 & 0,04 & 37,50 \\
\hline \multirow{3}{*}{ Dif. } & Avr. & $0,02 * *$ & 33,92 & $\begin{array}{l}54,98 \\
\end{array}$ & 33,92 & \multirow{3}{*}{ Dif. } & Avr. & $0,01^{* * *}$ & 24,75 & 54,98 & 32,31 \\
\hline & Min. & $0,00^{* *}$ & 5,17 & 10,00 & 5,17 & & Min. & $0,00^{* *}$ & 3,50 & 10,00 & 5,13 \\
\hline & Max. & $0,06^{* *}$ & 66,68 & 99,97 & 66,68 & & Max. & $0,03^{* *}$ & 50,00 & 99,96 & 62,50 \\
\hline
\end{tabular}

* Dif: Difference, Avr: Average, Min: Minimum, Max: Maximum, st: Slab thickness, sw: Slab width, ** Best equation value, units are $\mathrm{mm}$.

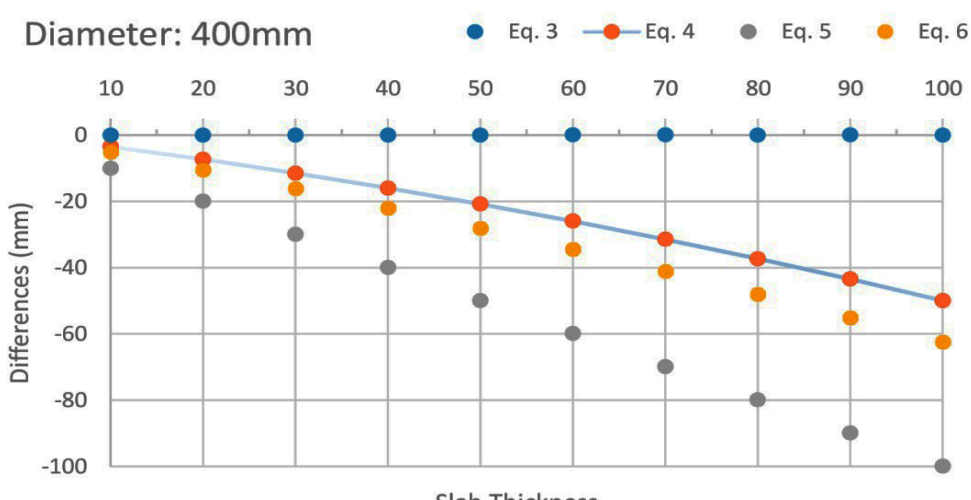

Slab Thickness

Figure 4: The estimated slab thickness differences according to equations in live sawing.

Results showed that Equation 3 (PWayBlog 2016) had the best accuracy (max. 0,06 mm, 0,02 mm in average difference) for the estimation slab thickness on both cross-sections. Because the equation had the lower differences and too close to real dimensions. It can be said that, the Equation 3 can be used for live sawing for estimating slab thickness and width (first board width at the same time). Other equations had bad estimations with up to $99,96 \mathrm{~mm}$ difference.

\section{Cant sawing}

Similar comparison was realized for cant sawing. Drawn and estimated cant widths (cw) were compared and results compared and shown in Table 2 and Figure 5. 
Table 2: Accuracies of the equations for cant sawing.

\begin{tabular}{|c|c|c|c|c|c|}
\hline \multirow{2}{*}{$\mathrm{ch}$} & \multicolumn{3}{|c|}{ Diameter $300 \mathrm{~mm}$} & \multicolumn{3}{c|}{ Diameter $400 \mathrm{~mm}$} \\
\cline { 2 - 3 } & Software & Pythagorean & & \multicolumn{2}{c|}{$\mathrm{cw}$} \\
\cline { 6 - 7 } & 280,00 & 280,00 & & Software & Pythagorean \\
\hline 107,7 & 24,9 & 380,00 & 380,00 \\
\hline 149,7 & 260,00 & 259,98 & 174,4 & 360,00 & 359,98 \\
\hline 180,0 & 240,00 & 240,00 & 210,7 & 340,00 & 340,01 \\
\hline 204,0 & 220,00 & 219,96 & 240,0 & 320,00 & 320,00 \\
\hline 223,6 & 200,00 & 200,01 & 264,6 & 300,00 & 299,98 \\
\hline 240,0 & 180,00 & 180,00 & 285,7 & 280,00 & 279,96 \\
\hline 253,8 & 160,00 & 159,95 & 304,0 & 260,00 & 259,97 \\
\hline 265,3 & 140,00 & 140,06 & 320,0 & 240,00 & 240,00 \\
\hline 275,0 & 120,00 & 119,90 & 334,1 & 220,00 & 219,95 \\
\hline 282,8 & 100,00 & 100,12 & 346,4 & 200,00 & 200,02 \\
\hline \multirow{3}{*}{ Dif. } & Average & 0,04 & & Average & 0,02 \\
\cline { 2 - 3 } \cline { 5 - 6 } & Min. & 0,00 & \multirow{2}{*}{ Dif. } & Min. & 0,00 \\
\cline { 2 - 3 } \cline { 5 - 6 } & Max. & 0,12 & & Max. & 0,05 \\
\hline
\end{tabular}

*Dif: Difference, Avr: Average, Min: Minimum, Max: Maximum, ch: Cant height, cw: Cant width.

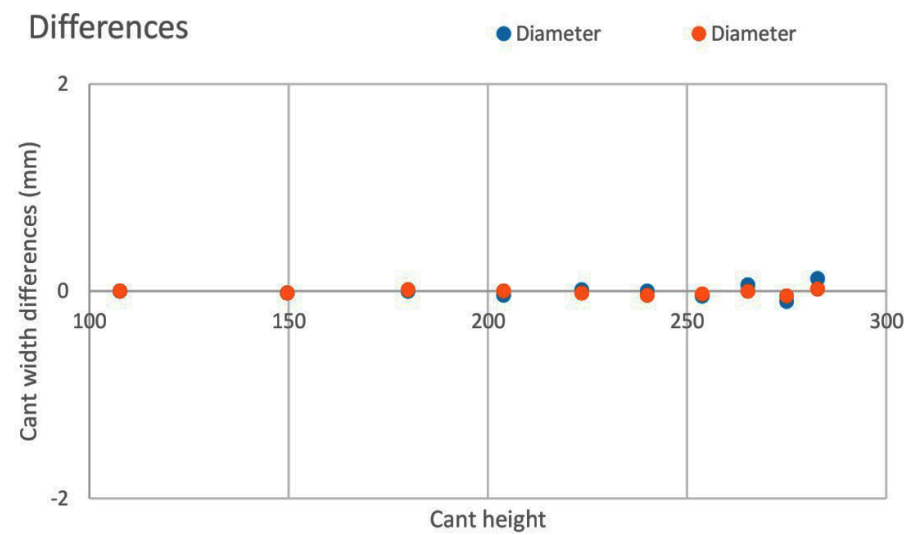

Figure 5: The estimated cant width differences in cant sawing.

Results showed that Pythagorean formula could estimate with high accuracy. In addition this, the results and drawings showed that cant width decreased related to slab thickness. This relation could be summarized with this Equation 12 and Figure 6.

$$
\mathrm{cw}=\text { Diameter }-(2 \mathrm{st})
$$

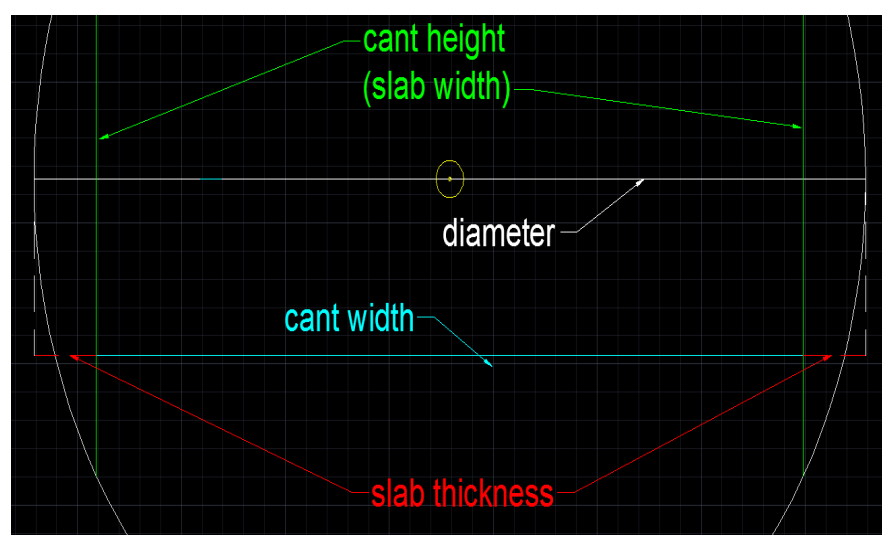

Figure 6: Slab thickness, diameter and cant width relation. 


\section{CONCLUSIONS}

The sawing process does not accept any fault with its unrepeatable characteristic. Therefore, Equation 3 (PWayBlog 2016) suggested with min. error of margin which negligible level for sawing process.

Results showed that one of versine equation can be used for log sawing optimization.

Using only the versine equation is enough on live sawing method for estimating slab thickness and width (first board width at the same time) while first sawing of the log. Pythagorean relation should be added for estimating cant and slab dimensions for cant sawing. Additionally, cant width could be estimated with slab thickness on cylindrical shaped cross-sections.

Logs with cylindrical shape were used for this study. Log defects can be added for further studies.

\section{ACKNOWLEDGEMENTS}

The data of this study was obtained from the Ph.D. thesis titled "Investigation on Optimization of Modern Lumber Manufacturing”.

\section{REFERENCES}

Auto CAD. 2013. AutoCAD 19,0. Autodesk: California, USA. https://knowledge.autodesk.com/support/ autocad

Bhandarkar, S.M.; Luo, X.; Daniels, R.; Tollner, E.W. 2008. Automated planning and optimization of lumber production using machine vision and computer tomography. IEEE Trans Autom Sci Eng 5(4): 677-695. https://doi.org/10.1109/tase.2008.925254

Boardman, H. 1930. Table For Use in Computing Arcs, Chords and Versines. Chicago Bridge and Iron Company:Chicago, USA. 32p

Chang, S.J.; Guddanti, S. 1995. TOPSAW-HW: A training and optimization system for sawing hardwood logs. In XX IUFRO World Forestry Congress, August. pp. 6-12. IUFRO: Vienna, Austria.

Chiou, S.B.; Yen, J.Y. 2019. Precise railway alignment measurements of the horizontal circular curves and the vertical parabolic curves using the chord method. Proceedings of the Institution of Mechanical Engineers, Part F: Journal of Rail and Rapid Transit 233(5): 537-549. https://doi.org/10.1177/0954409718800527

Faaland, B.; Briggs, D. 1984. Log bucking and lumber manufacturing using dynamic programming. Manage Sci 30(2): 245-247. https://doi.org/10.1287/mnsc.30.2.245

Hallock, H.; Lewis, D.W. 1971. Increasing softwood dimension yield from small logs: Best Opening Face. Vol. 166. Forest Products Laboratory, Forest Service, US Department of Agriculture: Madison, USA. https://www.fpl.fs.fed.us/documnts/fplrp/fplrp166.pdf

Hallock, H.; Stern, A.R.; Lewis, D.W. 1979. A look at centered vs. offset sawing (Vol. 321). Forest Products Laboratory, Forest Service, US Department of Agriculture: Madison, USA. https://www.fpl.fs.fed. us/documnts/fplrp/fplrp321.pdf

Haslett, C.W. 1859. The Mechanic's, Machinist's, and Engineer's Practical Book of Reference. WA Townsend: USA.

Holzman, D. 1958. Shen Kua and His Meng-Ch'i Pi-T'an. T'oung Pao. JSTOR 46(3/5): 260-292. www. jstor.org/stable/20185477

Inman, J. 1835. Navigation and Nautical Astronomy: For the Use of British Seamen. London, UK.

Iwnicki, S. 2006. Handbook of Railway Vehicle Dynamics. CRC Press. p. 448. https://doi.org/10.1201/9781420004892 
Korkut, S. 2004. Kayın Tomruklarının Biçilmesinde Korkut Randıman Optimizasyonu Paket Prog Kullanılması, Doğu Akdeniz Ormancilik Araştirma Müdürlüğü, Mersin, Turkey. Journal of DOA 10: 131-159.

Lewis, D.W. 1985. Sawmill simulation and the best opening face system: a user's guide. General technical report FPL-48. 29p. Madison, WI, USA. https://doi.org/10.2737/fpl-gtr-48

Lin, W.; Wang, J. 2012. An integrated 3D log processing optimization system for hardwood sawmills in central Appalachia, USA. Comput electron Agric 82: 61-74. https://doi.org/10.1016/j.compag.2011.12.014

Martín, I.F.; Vannoni, M.; Music, V.; Sinn, H. 2016. Characterization of a mechanical bender for Xray mirrors at European XFEL. Adaptive X-Ray Optics IV. San Diego, CA. USA. vol. 9965. pp. 996504 166.

Nair, P.N.B. 1972. Track measurement systems-concepts and techniques. Raíl International 3 (3): 159-

Needham, N.J.T.M. 1959. Science and Civilisation in China. Vol. 3: Mathematics and the Sciences of the Heavens and the Earth. Cambridge University Press. p. 39.

Occeña, L.G.; Tanchoco, J.M.A. 1988. Computer graphics simulation of hardwood log sawing. Forest Prod J 38(10): 72-76.

Occeña, L.G.; Schmoldt, D.L. 1995. GRASP-A Prototype Interactive Graphic Sawing Program. MU-IE Technical Report 019501. 17p, Blacksburg, USA. https://www.fs.usda.gov/treesearch/pubs/805

OpTimber. 2020. Guia de instruções do usuário: MaxiTora - Software de otimização de desdobro de toras, da empresa OpTimber, ambiente Windows. https://optimber.com.br/

P Way Blog. 2016. The versine formulae. https://pwayblog.com/2016/05/09/the-versine-formulae/

Romware. 2020. Sawmill - member of romware "decision on spot" solutions. Romware, Estonia. www. romware.eu

Saatech. 2020. PowerSAW, Software Version 1.0, Saatech Systems. http://saatech.com.au/create-sawing-patterns/

Tekl Studio. 2020. CutLog Timber sawing optimization software V 6.05.37334, Tek1 Studio Ltd.: Slovakia. https://cutlog.com

Todoroki, C.L. 1990. AUTOSAW system for sawing simulation. NZJ For Sci 20(3): 332-348. https://citeseerx.ist.psu.edu/viewdoc/download?doi=10.1.1.703.9966\&rep=rep1\&type=pdf

van Brummelen, G.R. 2013. Heavenly Mathematics: The Forgotten Art of Spherical Trigonometry. Princeton University Press: Princeton, USA.

Woodward, E. 1978. Geometry - Plane, Solid \& Analytic Problem Solver. Problem Solvers Solution Guides. Research \& Education Association (REA): New Jersey, USA. p. 359

Zheng, Y.; Wagner, F.G.; Steele, P.H.; Ji, Z. 2007. Two-dimensional geometric theory for maximizing lumber yield from logs. Wood Fiber Sci 21(1): 91-100. https://wfs.swst.org/index.php/wfs/article/view/1357 